\title{
Changes of Physicochemical and Microbiological Properties of Blended Sweet and Sour Pomegranate Juices during Refrigerated Storage
}

\author{
Faten Boussaa ${ }^{1 *}$, Faten Zaouay ${ }^{1}$, Messaoud Mars
}

\author{
1)Research Laboratory “Agrobiodiversity \& Ecotoxicology” (LR21AGR02), Higher Agronomic Institute, Chott-Mariem, \\ IRESA-University of Sousse, Tunisia \\ *) Correspondence Email: faten.boussaa@,laposte.net
}

\begin{abstract}
Physicochemical,microbiological and sensory properties changes of new beverages combining sweet ('Gabsi', 'Tounsi') and sour pomegranate juices ('Garoussi 2', 'Mezzi 1', 'Mezzi 2') with different proportions (10\% and 20\%) were studied over a 14 days refrigerated storage. The sour juices have proved to be very rich in total soluble solids, total anthocyanin and total phenolic contents. However, these juices are not appreciated by panelists because of high acidity content. The juice blends were characterized by an attractive red colour, acceptable acidity, higher total soluble solids content, higher total phenol and anthocyanin contents compared to sweet juices. The juice blending was found to be very effective in reducing the browning and improving the appearance of beverages during storage. The red colour and balanced sweet and sour taste were found the important criteria to determine the consumers' preference of beverages. The beverage based on Gabsi and Garoussi 2 (10\% and $20 \%$ proportions) presented a high total anthocyanin content resulting red colour and better microbiological stability during storage leading to their high consumer acceptance. It was concluded that conservation of juice samples should not exceed 7 days to have healthy value-added beverages.
\end{abstract}

Keywords: Punica granatum; functional beverages; cold storage; physicochemical properties; bacteria

\section{INTRODUCTION}

Nowadays, the interest in the role of dietary antioxidants in human health has prompted research in the field of food science (Gonzalez-Molina et al., 2009). An increasing consumer demand for pomegranate (Punica granatum L.) has been globally observed, mainly thanks to the scientific evidence related to its functional and health-promoting features (Pontonio et al., 2019). Pomegranate fruits are not only consumed fresh but also used to produce jam, jelly, syrup and several types of soft drinks (Vardin and Fenercioglu, 2003; Zaouay et al., 2014). Pomegranate juice has been rated to contain the highest antioxidant capacity compared to other commonly consumed polyphenol rich beverages including red wine, berry fruit juices and green tea (Seeram et al., 2008). This potent antioxidant activity has been related to a diverse group of polyphenols including ellagitannins, gallotannins, ellagic acid and flavonoids, such as anthocyanins. Besides the antioxidant activity, pomegranate juice has shown chemopreventive effects such as antiatherogenic, antihypertensive and anti-inflammatory properties (Zarfeshany et al., 2014).

Pomegranate (Punica granatum L.) has been traditionally cultivated since ancient times under diverse climatic conditions in Tunisia. Mars (2001) has identified more than 40 ecotypes denominated mainly according to their geographical origin as well as their fruit colour. In spite of the large number of local cultivars, very few are commercially utilized. Many sour cultivars are becoming abandoned despite their high potential of valorization. Their high acidity could be an interesting trait for several purposes. Also, Tunisian sour pomegranate cultivars have high sugar content (Hasnaoui et al., 2011) and were rich in polyphenols as well as anthocyanins, ascorbic acid and mineral contents (Zaouay et al., 2014). Our research was focused on providing a new beverage combining sour and sweet pomegranate juices for improving sensory and nutritional aspects.
In recent years consumers have increasingly sought so-called "fresh" products stored in refrigeration. Keeping the juice at lower temperatures will prevent flavor deterioration due to thermo-resistant bacteria (Hossain et al., 2016). However, fruit juice shelf life under refrigeration has been reported to be short (De Corrêa Souza et al., 2004). The main requirement is to ensure product microbial safety while preserving sensory and nutritional characteristics so as to obtain products as similar as possible to fresh foods.

Therefore, in this study, physico-chemical,microbiological and sensory properties assessment of pure and mixed juices was carried out. Also, storage stability of beverages kept at refrigeration temperature $\left(4^{\circ} \mathrm{C}\right)$ for two weeks was studied.

\section{MATERIALS AND METHODS}

\section{Plant material}

Pomegranate fruits were collected from five pomegranate varieties growing in the same ex-situ collection in Gabès (south Tunisia). Two sweet varieties (Gabsi, GB and Tounsi, TN) and three sour varieties (Garoussi 2, GR2; Mezzi 1, MZ1 and Mezzi 2, MZ2) were used. From each variety, ripe fruits were harvested at the beginning of October and immediately transported to the laboratory. Pomegranates with defects (sunburns, cracks, cuts and bruises in husk) were discarded.

\section{Sample preparation}

From each variety, healthy pomegranates were washed with water containing drops of bleach to remove dust particles and reduce the microbial load on the fruit surface. Fruits were manually peeled and juices were extracted from fleshy arils using an electric juice centrifuge.

Sweet pomegranate juices (Gabsi and Tounsi) were used as the reference juices to which sour pomegranate juices (Garoussi 2, Mezzi 1, Mezzi 2) were added at different proportions ( $10 \%$ and $20 \%)$. Finally, we got 3 types of juices: pure juices, juices mixed with $10 \%$ of sour juices (GR2, MZ1 
and MZ2; $315 \mathrm{ml}$ of sweet juice mixed with $35 \mathrm{ml}$ of sour juice) and juices mixed with $20 \%$ of sour juices (GR2, MZ1 and MZ2; $280 \mathrm{ml}$ of sweet juice mixed with $70 \mathrm{ml}$ of sour juice).

Physicochemical, microbiological and sensory analyses were carried out on each fresh and stored pure juices and mixtures. Juice samples intended for storage were placed in plastic bottles $(350 \mathrm{ml})$ and were kept in a refrigerator at $4{ }^{\circ} \mathrm{C}$ for one week or 14 days.

\section{Colour, pH, titratable acidity, total soluble solids}

Juice colour (JC) was assessed visually according to grading scale of colour intensity ranging from 2 (light pink: the lightest color) to 18 (reddish purple: the darkest color). The juice browning degree was estimated according to a scale of 6 points, where 0 : no browning; 1: very low browning, 2 : low browning; 3: moderate browning; 4: high browning and 5: very high browning.

Juice $\mathrm{pH}$ was measured using a pH-meter (Jenway 4320). Titratable acidity (TA) was determined by acid-base potentiometry $(0.1 \mathrm{~mol} \mathrm{~L}-1 \mathrm{NaOH}$ up to $\mathrm{pH} 8.1)$ and expressed as percentage of malic acid in the juice. Total soluble solids content was recorded using a digital refractometer (PAL-1-ATAGO) at $20^{\circ} \mathrm{C}$ and values were expressed as ${ }^{\circ}$ Brix. All measurements were repeated thrice.

\section{Total anthocyanin content (TAC)}

Total anthocyanin content (TAC) was determined by the $\mathrm{pH}$ differential method (Cheng and Breen, 1991). Anthocyanins were analyzed in triplicate: $0.4 \mathrm{~mL}$ of pomegranate juice was diluted in $3.6 \mathrm{~mL}$ of two different buffers: potassium chloride $(0.025 \mathrm{M}, \mathrm{pH} 1.0)$ and sodium acetate $(0.4 \mathrm{M}, \mathrm{pH} 4.5)$. The absorbance $(\mathrm{A})$ of two dilutions was determined at 510 and $700 \mathrm{~nm}$, where $\mathrm{A}=\left(\mathrm{A}_{510 \mathrm{~nm}}-\mathrm{A}_{700 \mathrm{~nm}}\right)_{\mathrm{pH} 1.0}-\left(\mathrm{A}_{510 \mathrm{~nm}}-\mathrm{A}_{700 \mathrm{~nm}}\right)_{\mathrm{pH} 4.5}$ The content of total anthocyanins (mg cyanidin-3glucoside $/ \mathrm{L})$ was calculated as: $\mathrm{TAC}=(\mathrm{A} \times \mathrm{MW} \times \mathrm{DF} \times$ $1000) /(\varepsilon \times 1)$, with a dilution factor (DF) of 10 , an extinction coefficient $(E)$ of $26,900 \mathrm{~L}$ mol-1 cm-1 and a molecular weight (MW) of $449.2 \mathrm{~g}$ mol-1.

\section{Total phenolic content (TPC)}

Total phenol content was determined according to the Folin-Ciocalteu method (Arnous et al., 2001). In a $1.5 \mathrm{ml}$ Eppendorf microtube, $790 \mu \mathrm{l}$ of distilled water, $10 \mu \mathrm{l}$ of sample appropriately diluted and $50 \mu \mathrm{l}$ of Folin-Ciocalteu reagent were added and vortexed. After $1 \mathrm{~min}, 150 \mu \mathrm{l}$ of aqueous $20 \%$ sodium carbonate were added, vortexed again and allowed to stand at room temperature in the dark, for 2 hours. Reaction was followed with a spectrophotometer (Spectrumlab 22 PC). The absorbance was recorded at 750 $\mathrm{nm}$ and quantified using gallic acid as a standard. Results were expressed as $\mathrm{mg}$ of gallic acid equivalents (GAE) per $100 \mathrm{ml}$

\section{Microbiological analysis}

The total count of bacteria was determined on Plate Count Agar (PCA). Using sterile distilled water, serial dilutions were prepared from each of the juice samples. Duplicates of each dilution $(1 \mathrm{~mL})$ were pour-plated in Standard Methods Agar and incubated at 37 for $48 \mathrm{~h}$ (aerobic cultivation method). The plates with colony forming units per $\mathrm{mL}$ (CFU/mL) ranging from 30-300 were considered for counting (Nayik et al., 2014). A microscopic observation was also performed to describe the characteristics of different colonies growing on agar in a Petri dish.

\section{Sensory Evaluation}

A group of 100 panelists (aged between 20 and 55 years) consisting of the staff and students of High Agronomic Institute of Chott-Mariem (Tunisia) participated in taste panels. Consumers were asked to describe the appreciation degree for colour, aroma, sourness, sweetness and their overall liking. A 9-point hedonic scale was used for this test (1 $=$ dislike extremely, $5=$ neither like nor dislike, $9=$ like extremely). Juice samples were presented in identical containers identified with 3-digit random codes and were placed in a randomized order. Unsalted crackers and spring water were provided to panelists to clean their palates between samples.

\section{Statistical Analysis}

Statistical analyses were performed using one-way analysis of variance ANOVA, and the significant differences between means were determined by Duncan's multiple range test using SPSS 20 software. Significance was defined at $\mathrm{P}<0.05$. Pearson's correlation test was used to determine whether there were any significant relationships between the physicochemical and sensory parameters.

\section{RESULT AND DISCUSSION}

\section{Colour, pH, Titratable acidity and Total soluble solids}

An attractive red colour is one of the most important quality criteria for fruit juices including pomegranate juice. The sweet juices 'Gabsi' and 'Tounsi' exhibited a reddish pink and purplish red colour, respectively. The bright red colour is associated to sour pomegranate juices 'Garoussi 2' and 'Mezzi 2 '. The juice blending improved the colour of mixtures proportionally to the percentage of sour juice (Table 1). During the first 7 days of storage, a little visual brown colour was observed in pure juices 'Gabsi' and 'Tounsi' as well as sweet juices mixed with $10 \%$ of sour juices 'Mezzi 1' and 'Mezzi 2'. Browning degree continues to increase significantly after 14 days of storage. These results are consistent with those of Rommel et al. (1990) who reported that the red pigments in raspberry and other fruits degraded and polymerized easily with the influence of temperature and storage duration. The anthocyanin polymerization leads to the formation of an insoluble red-brown precipitate as an end product of anthocyanin degradation (Boulton, 2001). Also, the reaction of phenolic compounds to form brown polymeric compounds may play a major role in colour deterioration (Bhardwaj and Mukherjee, 2011). However, juice blends containing $20 \%$ of sour juices were more stable and retained better their attractive red colour even after two weeks of storage. Thus, the colour of anthocyanins is depending on the $\mathrm{pH}$ of the solution. In acidic condition, some of the anthocyanins appear red. At lower $\mathrm{pH}$, the flavylium cation formed enables the anthocyanin to be highly soluble in water. The decrease in water concentration increases the rate of deprotonation of the flavylium cation, thus reducing colour stability (Coutinho et al., 2015; Khoo et al., 2017).

Juice $\mathrm{pH}$, titratable acidity (TA) and total soluble solids content (TSS) were also affected by juice blending and storage duration (Table 2). The sweet juices 'Gabsi' and 'Tounsi' presented $\mathrm{pH}$ values 4.28 and 4.22, respectively. However, lower $\mathrm{pH}$ values $(3.45,3.53$ and 3.47) were recorded for sour juices 'Garoussi 2', 'Mezzi 1' and 'Mezzi 2', respectively. Consequently, there was a significant decrease of mixed juice $\mathrm{pH}$ values with the increase of sour juice percentage. The juice 'Gabsi' mixed with 20\% of sour juice 'Mezzi 1' (GB-MZ1 20 $\%$ ) was characterized by the lowest $\mathrm{pH}$ value (3.64). 
Regarding titratable acidity (TA), the sour juice 'Mezzi 2' showed the highest acidity $(2.17 \%)$ while the lowest was observed in the sweet juice 'Gabsi' $(0.13 \%)$. The blending of sweet and sour pomegranate juices generated an increase in the acidity proportionally to the added sour juice percentage. In mixtures, the titratable acidity values varied from $0.21 \%$ for 'Gabsi' juice mixed with $10 \%$ of 'Garoussi 2' (GB-GR2 $10 \%$ ) to $0.49 \%$ for 'Tounsi' juice mixed with $20 \%$ of 'Mezzi2' (TN-MZ2 20\%). During storage at $4{ }^{\circ} \mathrm{C}$, fluctuations in the acidity content were observed for all juice samples (Table 2).
At the first 7 days, most juice samples showed a decrease in the acidity content. This could be related to conversion of acids into salts and sugars by enzymes particularly invertase (Bhardwaj and Mukherjee, 2011). A prolonged storage up to 14 days resulted in an increase in titratable acidity for pure juice 'Gabsi', sour juices and Gabsi mixtures (GB-MZ1 10\%, GB-MZ1 20\% and GB-MZ2 10\%). However, pure and mixture juices 'Tounsi' showed no significant variation of titratable acidity during the last 7 days of storage (Table 2).

Table 1. Juice colour variation according to juice blending and storage duration

\begin{tabular}{|c|c|c|c|}
\hline Juice type & Fresh juice & 7 days of storage & 14 days of storage \\
\hline Gabsi & 16 Reddish pink & $\mathrm{BD}: 2$ & BD: 3 \\
\hline Tounsi & 18 Purplish red & $\mathrm{BD}: 3$ & $\mathrm{BD}: 4$ \\
\hline GR2 & 17 Bright red & 17 Bright red & 17 Bright red \\
\hline $\mathrm{MZ1}$ & 16 Reddish pink & 16 Reddish pink & 14 Reddish pink \\
\hline $\mathrm{MZ2}$ & 17 Bright red & 17 Bright red & 17 Bright red \\
\hline GB-GR2 10\% & 16 Reddish pink & BD: 1 & BD: 2 \\
\hline GB-GR2 20\% & 17 Bright red & 17 Bright red & 16 Reddish pink \\
\hline GB-MZ1 $10 \%$ & 16 Reddish pink & 16 Reddish pink & $\mathrm{BD}: 2$ \\
\hline GB-MZ1 20\% & 17 Bright red & 17 Bright red & 17 Bright red \\
\hline GB-MZ2 $10 \%$ & 16 Reddish pink & $\mathrm{BD}: 3$ & $\mathrm{BD}: 3$ \\
\hline GB-MZ2 20\% & 17 Bright red & 17 Bright red & 17 Bright red \\
\hline TN-GR2 10\% & 16 Reddish pink & BD: 1 & $\mathrm{BD}: 1$ \\
\hline TN-GR2 20\% & 17 Bright red & 17 Bright red & 17 Bright red \\
\hline TN-MZ1 $10 \%$ & 17 Bright red & BD: 1 & BD: 2 \\
\hline TN-MZ1 20\% & 17 Bright red & 17 Bright red & 17 Bright red \\
\hline TN-MZ2 10\% & 17 Bright red & BD: 1 & BD: 1 \\
\hline TN-MZ2 20\% & 17 Bright red & 17 Bright red & 17 Bright red \\
\hline
\end{tabular}

GB: Gabsi, TN: Tounsi, GR2: Garoussi 2, MZ1: Mezzi 1, MZ2: Mezzi 2, BD: Browning degree

The total soluble solids content (TSS) varied significantly according to juice blending and storage duration (Table 2). The TSS content ranged from 14.6-15.4 ${ }^{\circ}$ Brix for sweet juices 'Gabsi' and 'Tounsi' to $16.97-18.13{ }^{\circ}$ Brix for sour juices 'Garoussi 2' and 'Mezzi 2', respectively. The juice blends showed an increase of TSS content proportionally to the percentage of sour juice added. The mixture Tounsi Mezzi 2 20\% (TN-MZ2 20\%) had a significantly higher TSS content (16.10 ${ }^{\circ}$ Brix) compared to other mixtures (Table 2). A decrease in total soluble solids content was observed in most juice samples after 14 days storage. The pure juice 'Gabsi' and some of its mixtures presented greater decrease in TSS content during storage. However, the sour juice 'Garoussi 2' showed an increase in TSS content while it did not change for sweet juice 'Tounsi' after 14 days of storage. Also, the sweet juices 'Gabsi' and 'Tounsi' mixed each one with $10 \%$ of sour juice 'Garoussi 2' did not show any significant variation during refrigerated storage. Wisal et al. (2013) reported that the decrease in TSS content in strawberry juice after refrigerated storage might be due to the breakdown of polysaccharides or oxidation of reducing sugars and their conversion in acids. Also, this decrease may be attributed to fermentative metabolism of sugars and other essential nutrients such as amino acids, minerals and vitamins into ethanol and carbon dioxide by yeasts particularly Saccaromyces cerevisiae (Walker and Stewart, 2016).

\section{Total phenolic content}

The total phenolic content (TPC) was significantly affected by juice blending and storage duration (Table 3 ). The TPC in sweet pomegranate juices varied from $251.1 \mathrm{mg} / 100 \mathrm{ml} \mathrm{GAE}$ for 'Gabsi' to $271.8 \mathrm{mg} / 100 \mathrm{ml} \mathrm{GAE}$ for 'Tounsi'. However, sour pomegranate juices had higher values ranging from 302.2 to $344.1 \mathrm{mg} / 100 \mathrm{ml}$ GAE. In the juice blends, the total phenolic content increased proportionally to the percentage of sour juice. In addition, refrigerated storage resulted in phenolic content changes depending on variety and juice type (Table 3). During 7 days of storage, total phenolic content increased in the most of juice samples. After 14 days, a significant decrease of TPC was observed in some juice samples. However, the juices 'Gabsi', 'Garoussi 2', 'Mezzi 2', 'TN-MZ1 10\%' and 'TN-MZ2 20\%' presented an increase in total phenolic content. Galani et al. (2017) revealed that the storage of fruits and vegetables at $4{ }^{\circ} \mathrm{C}$ during 15 days significantly decreased their TP content. An increase in total phenolic content was found to be associated with an increase in the PAL (phenylalanine ammonia lyase) enzymatic activity after 5 days storage at $5^{\circ} \mathrm{C}$ (Vitti et al., 2011). However, a gradual loss of total phenols during storage might be due to their condensation into brown pigments (Karpagavalli and Amutha, 2015). 
Table 2. Changes in titratable acidity, $\mathrm{pH}$, total soluble solids of pure juices and juice blends during refrigerated storage

\begin{tabular}{|c|c|c|c|c|c|c|c|c|c|}
\hline \multirow[b]{2}{*}{ Juice type } & \multicolumn{3}{|c|}{ Titratable acidity (TA) } & \multicolumn{3}{|c|}{$\mathrm{pH}$} & \multicolumn{3}{|c|}{ Total soluble solids (TSS) } \\
\hline & Fresh juice & $\begin{array}{l}7 \text { days of } \\
\text { storage }\end{array}$ & $\begin{array}{l}14 \text { days of } \\
\text { storage }\end{array}$ & Fresh juice & $\begin{array}{l}7 \text { days of } \\
\text { storage }\end{array}$ & $\begin{array}{l}14 \text { days of } \\
\text { storage }\end{array}$ & Fresh juice & $\begin{array}{l}7 \text { days of } \\
\text { storage }\end{array}$ & $\begin{array}{l}14 \text { days of } \\
\text { storage }\end{array}$ \\
\hline Gabsi & $0.13 \pm 0.06^{k B}$ & $0.13 \pm 0.006^{k B}$ & $0.20 \pm 0.07^{j k A}$ & $4.28 \pm 0.01^{a A}$ & $4.29 \pm 0.01^{a A}$ & $4.23 \pm 0.23^{a A}$ & $14.60 \pm 0.21^{h B}$ & $15.30 \pm 0.0^{\text {bcdeA }}$ & $13.07 \pm 0.3^{k C}$ \\
\hline Tounsi & $0.17 \pm 0.06^{\mu}$ & $0.17 \pm 0.006^{j A}$ & $0.17 \pm 0.003^{k 4}$ & $4.22 \pm 0.006^{b B}$ & $4.24 \pm 0.00^{a b A}$ & $4.22 \pm 0.06^{a B}$ & $15.40 \pm 0.00^{6 A}$ & $15.10 \pm 0.0^{c d f f A}$ & $14.30 \pm 0.0^{g A-}$ \\
\hline GR2 & $1.96 \pm 0.25^{c A}$ & $1.62 \pm 0.009^{b B}$ & $2.01 \pm 0.006^{\mathrm{ct}}$ & $3.45 \pm 0.009^{n A}$ & $3.55 \pm 0.58^{i 4}$ & $3.20 \pm 0.03^{i B}$ & $16.97 \pm 0.03^{b A}$ & $14.80 \pm 0.62^{e A B}$ & $16.40 \pm 0.6^{b A}$ \\
\hline MZ1 & $2.13 \pm 0.03^{b B}$ & $2.13 \pm 0.006^{a B}$ & $2.16 \pm 0.003^{b A}$ & $3.53 \pm 0.02^{m 4}$ & $3.49 \pm 0.02^{/ 4}$ & $3.26 \pm 0.22^{h B}$ & $14.97 \pm 0.12^{g A}$ & $14.83 \pm 0.44^{e / 4}$ & $12.87 \pm 0.3^{I B}$ \\
\hline MZ2 & $2.17 \pm 0.06^{a A}$ & $2.14 \pm 0.009^{a B}$ & $2.18 \pm 0.003^{a A}$ & $3.47 \pm 0.0^{n B}$ & $3.56 \pm 0.02^{i A}$ & $3.21 \pm 0.10^{x}$ & $18.13 \pm 0.22^{a 4}$ & $17.10 \pm 0.21^{a B}$ & $16.73 \pm 0.3^{a B}$ \\
\hline GB-GR2 10\% & $0.21 \pm 0.09^{i B}$ & $0.26 \pm 0.06^{f g 4}$ & $0.27 \pm 0.007^{h A}$ & $3.97 \pm 0.006^{\complement C}$ & $4.21 \pm 0.01^{b A}$ & $4.12 \pm 0.06^{b B}$ & $15.03 \pm 0.06^{g A}$ & $15.07 \pm 0.35^{d f f A}$ & $14.67 \pm 0.3^{f A}$ \\
\hline GB-GR2 20\% & $0.32 \pm 0.26^{g A}$ & $0.32 \pm 0.013^{e t}$ & $0.34 \pm 0.006^{f A}$ & $3.71 \pm 0.006^{C}$ & $4.03 \pm 0.03^{\text {det }}$ & $3.99 \pm 0.09^{d B}$ & $15.03 \pm 0.15^{a b B}$ & $15.40 \pm 0.2^{\text {bcdeA }}$ & $14.07 \pm 0.3^{i C}$ \\
\hline GB-MZ1 10\% & $0.28 \pm 0.03^{h B}$ & $0.25 \pm 0.03^{f_{8} C}$ & $0.34 \pm 0.003^{f A}$ & $3.86 \pm 0.003^{d B}$ & $3.95 \pm 0.0^{f A}$ & $3.93 \pm 0.09^{e A}$ & $14.57 \pm 0.40^{h t}$ & $14.53 \pm 0.06^{f A}$ & $13.30 \pm 0.1^{f^{B}}$ \\
\hline GB-MZ1 20\% & $0.40 \pm .06^{f B}$ & $0.39 \pm 0.009^{d B}$ & $0.43 \pm 0.009^{d e A}$ & $3.64 \pm 0.015^{f C}$ & $3.78 \pm 0.09^{h 4}$ & $3.73 \pm 0.03^{g B}$ & $14.87 \pm 0.25^{g h t}$ & $14.93 \pm 0.06^{e / 4}$ & $12.93 \pm 0.3^{I B}$ \\
\hline GB-MZ2 10\% & $0.28 \pm 0.0^{h B}$ & $0.27 \pm 0.003^{f B}$ & $0.31 \pm 0.007^{\mathrm{A}}$ & $3.89 \pm 0.00^{\circ C}$ & $4.06 \pm 0.13^{a / A}$ & $4.00 \pm 0.03^{d B}$ & $15.00 \pm 0.17^{8 A}$ & $15.07 \pm 0.06^{d e f A}$ & $14.17 \pm 0.3^{h i B}$ \\
\hline GB-MZ2 20\% & $0.40 \pm 0.03^{f 4}$ & $0.39 \pm 0.00^{d A}$ & $0.42 \pm 0.032^{e A}$ & $3.66 \pm 0.03^{k C}$ & $3.75 \pm 0.03^{h A}$ & $3.70 \pm 0.0^{8 B}$ & $15.13 \pm 0.06^{\text {SBA }}$ & $14.73 \pm 0.06^{e A B}$ & $14.20 \pm 0.6^{g h c}$ \\
\hline TN-GR2 10\% & $0.29 \pm 0.12^{\text {ght }}$ & $0.23 \pm 0.006^{A B}$ & $0.23 \pm 0.00^{i B}$ & $3.94 \pm 0.006^{d B}$ & $4.10 \pm 0.03^{c t}$ & $4.10 \pm 0.03^{b A}$ & $15.73 \pm 0.07^{d A A}$ & $15.63 \pm 0.03^{\text {bcdA }}$ & $15.60 \pm 0.0^{c A}$ \\
\hline TN-GR2 20\% & $0.45 \pm 0.07^{e A}$ & $0.30 \pm 0.01^{e B}$ & $0.31 \pm 0.006^{g B}$ & $3.72 \pm 0.006^{y B}$ & $3.85 \pm 0.06^{8 A}$ & $3.84 \pm 0.06^{f A}$ & $15.63 \pm 0.03^{\text {deB }}$ & $15.73 \pm 0.03^{\text {bCA }}$ & $15.60 \pm 0.0^{c B}$ \\
\hline TN-MZ1 10\% & $0.32 \pm 0.06^{g A}$ & $0.25 \pm 0.02^{g h B}$ & $0.25 \pm 0.046^{h B}$ & $3.91 \pm 0.007^{e s}$ & $3.99 \pm 0.06^{e f A}$ & $4.01 \pm 0.06^{d 4}$ & $15.57 \pm 0.07^{d k B}$ & $15.80 \pm 0.00^{b A}$ & $15.67 \pm 0.3^{\text {cAB }}$ \\
\hline TN-MZ1 20\% & $0.48 \pm 0.03^{\text {des }}$ & $0.44 \pm 0.01^{c B}$ & $0.45 \pm 0.006^{d \mathrm{~B}}$ & $3.77 \pm 0.003^{h A}$ & $3.73 \pm 0.06^{h B}$ & $3.72 \pm 0.06^{g B}$ & $15.40 \pm 0.0^{e \mathcal{C}}$ & $15.93 \pm 0.03^{b A}$ & $15.70 \pm 0.0^{c B}$ \\
\hline TN-MZ2 10\% & $0.31 \pm 0.03^{g h t}$ & $0.23 \pm 0.00^{h B B}$ & $0.22 \pm 0.01^{j \beta B}$ & $3.93 \pm 0.006^{d e C}$ & $4.06 \pm 0.06^{a / A}$ & $4.04 \pm 0.06^{c B}$ & $15.80 \pm 0.0^{\text {cat }}$ & $15.63 \pm 0.03^{b c d B}$ & $15.00 \pm 0.0^{e C}$ \\
\hline TN-MZ2 20\% & $0.49 \pm 0.07^{d A}$ & $0.32 \pm 0.006^{e B}$ & $0.32 \pm 0.0^{f_{8} B}$ & $3.74 \pm 0.00^{i B}$ & $3.87 \pm 0.03^{g A}$ & $3.86 \pm 0.06^{f 4}$ & $16.10 \pm 0.0^{c A}$ & $15.77 \pm 0.03^{b B}$ & $15.40 \pm 0.0^{d C}$ \\
\hline
\end{tabular}

Different lowercase letters within a same column indicate significant differences among juice types for each storage duration at $\mathrm{P}<0.05$ level.

Different uppercase letters within a same row indicate significant differences among storage duration treatments for each juice type at $\mathrm{P}<0.05$ level.

GB: Gabsi, TN: Tounsi, GR2: Garoussi 2, MZ1: Mezzi 1, MZ2: Mezzi 2, TA: Titratable acidity, TSS: Total soluble solids

Table 3. Changes in total anthocyanin and phenolic contents of pure juices and juice blends during refrigerated storage

\begin{tabular}{|c|c|c|c|c|c|c|}
\hline & \multicolumn{3}{|c|}{ Total anthocyanin content } & \multicolumn{3}{|c|}{ Total phenolic content } \\
\hline & Fresh juice & $\begin{array}{l}7 \text { days of } \\
\text { storage }\end{array}$ & $\begin{array}{l}14 \text { days of } \\
\text { storage }\end{array}$ & Fresh juice & $\begin{array}{c}7 \text { days of } \\
\text { storage }\end{array}$ & $\begin{array}{c}14 \text { days of } \\
\text { storage }\end{array}$ \\
\hline Gabsi & $9.82 \pm 0.1^{i B}$ & $8.93 \pm 0.02^{f C}$ & $13.87 \pm 0.05^{d A}$ & $251.09 \pm 3.6^{g A}$ & $219.05 \pm 3.43^{i B}$ & $255.9 \pm 1.5^{f A}$ \\
\hline Tounsi & $14.79 \pm 0.5^{f A}$ & $7.0 \pm 0.01^{g h C}$ & $7.62 \pm 0.07^{i B}$ & $271.83 \pm 4^{f B}$ & $382.14 \pm 6.2^{b A}$ & $279.1 \pm 0.5^{d B}$ \\
\hline GR2 & $71.47 \pm 0.87^{a A}$ & $66.80 \pm 0.05^{a B}$ & $71.64 \pm 0.2^{a A}$ & $302.2 \pm 4.8^{d e B}$ & $310.71 \pm 6.18^{f B}$ & $755 \pm 2.75^{a A}$ \\
\hline MZ1 & $48.18 \pm 0.92^{b A}$ & $47.93 \pm 1.74^{b A}$ & $48.26 \pm 0.3^{b A}$ & $322.3 \pm 6.7^{c B}$ & $410.71 \pm 2.8^{a A}$ & $232.1 \pm 2.6^{h i C}$ \\
\hline $\mathrm{MZ2}$ & $35.99 \pm 0.44^{c B}$ & $37.74 \pm 0.77^{c B}$ & $41.58 \pm 0.2^{c A}$ & $344.1 \pm 0.7^{b B}$ & $354.76 \pm 4.1^{c B}$ & $747.6 \pm 1.9^{a A}$ \\
\hline GB-GR2 10\% & $6.34 \pm 0.12^{j B}$ & $6.69 \pm 0.24^{h B}$ & $9.49 \pm 0.10^{h A}$ & $288.1 \pm 2.7^{e B}$ & $403.24 \pm 4.1^{a A}$ & $203.6 \pm 0.7^{k C}$ \\
\hline GB-GR2 20\% & $10.87 \pm 0.4^{h A}$ & $7.57 \pm 0.06^{\text {efghB }}$ & $9.13 \pm 0.05^{i A}$ & $303.9 \pm 9.2^{d B}$ & $337.81 \pm 3.8^{d A}$ & $225 \pm 2.06^{i j C}$ \\
\hline GB-MZ1 $10 \%$ & $11.69 \pm 0.3^{g h t}$ & $7.4 \pm 0.07^{f g h C}$ & $10.63 \pm 0.1^{f B}$ & $393.26 \pm 6^{a A}$ & $253.57 \pm 3.4^{h B}$ & $219.1 \pm 0.82^{j B}$ \\
\hline GB-MZ1 20\% & $12.04 \pm 0.2^{g A}$ & $9.07 \pm 0.07^{e C}$ & $10.06 \pm 0.5^{g B}$ & $267.93 \pm 11^{f A}$ & $248.81 \pm 4.8^{h A}$ & $247.8 \pm 3.5^{g A}$ \\
\hline GB-MZ2 10\% & $11.56 \pm 0.1^{g h A}$ & $11.53 \pm 0.08^{d A}$ & $10.98 \pm 0.02^{e C}$ & $242.86 \pm 4^{g h B}$ & $321.43 \pm 2.7^{e f A}$ & $189.29 \pm 3^{I C}$ \\
\hline GB-MZ2 20\% & $12.31 \pm 0.24^{g A}$ & $11.63 \pm 0.07^{d B}$ & $11.0 \pm 0.09^{e B}$ & $228.6 \pm 0$ hiC & $331.76 \pm 4.6^{d e A}$ & $287.85 \pm 1.76^{\mathrm{c}^{B}}$ \\
\hline TN-GR2 10\% & $15.66 \pm 0.5^{e f A}$ & $6.7 \pm 0.01^{h C}$ & $7.79 \pm 0.01^{j B}$ & $234.2 \pm 2.3^{h i B}$ & $344.44 \pm 4.7^{c d A}$ & $238.8 \pm 0.6^{h B}$ \\
\hline TN-GR2 20\% & $16.95 \pm 0.14^{d A}$ & $8.48 \pm 0.12^{e f g B}$ & $7.9 \pm 0.02^{j C}$ & $352.38 \pm 5^{b A}$ & $284.52 \pm 4.8^{g B}$ & $272.6 \pm 1^{d e C}$ \\
\hline TN-MZ1 10\% & $15.14 \pm 0.9^{e f A}$ & $8.02 \pm 0.04^{\text {efgh } B}$ & $7.53 \pm 0.01^{j c}$ & $265.5 \pm 1.8^{f C}$ & $352.38 \pm 1.3^{c B}$ & $408.3 \pm 2.6^{b A}$ \\
\hline TN-MZ1 20\% & $16.09 \pm 0.15^{\text {deA }}$ & $11.23 \pm 0.01^{d B}$ & $10.7 \pm 0.09^{e f C}$ & $310.7 \pm 0.7^{c d A}$ & $310.52 \pm 6.03^{f A}$ & $269.1 \pm 1.3^{e B}$ \\
\hline TN-MZ2 10\% & $14.91 \pm 0.12^{f A}$ & $8.27 \pm 0.05^{e f g B}$ & $7.76 \pm 0.09^{j C}$ & $221.19 \pm 3.7^{i B}$ & $345.14 \pm 4.7^{c d A}$ & $219.05 \pm 5.4^{j B}$ \\
\hline TN-MZ2 20\% & $15.01 \pm 0.07^{e f A}$ & $8.37 \pm 0.05^{e f g B}$ & $7.9 \pm 0.09^{j C}$ & $228.57 \pm 1.2^{\text {hiAB }}$ & $207.14 \pm 4.13^{i B}$ & $279.3 \pm 4.6^{d A}$ \\
\hline
\end{tabular}

Different lowercase letters within a same column indicate significant differences among juice types for each storage duration at $\mathrm{P}<0.05$ level.

Different uppercase letters within a same row indicate significant differences among storage duration treatments for each juice type at $\mathrm{P}<0.05$ level.

GB: Gabsi, TN: Tounsi, GR2: Garoussi 2, MZ1: Mezzi 1, MZ2: Mezzi 2 


\section{Total Anthocyanin Content}

Anthocyanins are colored water-soluble pigments that give various beneficial health effects due to their potent antioxidant capacity (Khoo et al., 2017). The total anthocyanin content ranged from $9.82 \mathrm{mg} / 100 \mathrm{ml}$ to 71.47 $\mathrm{mg} / 100 \mathrm{ml}$ (Table 3 ). The sour pomegranate juices exhibited higher anthocyanin contents than those recorded in sweet pomegranate juices 'Gabsi' and 'Tounsi'. The juice blends showed a significant increase of total anthocyanin content proportionally to the percentage of sour juice. These results were in agreement with those of Zaouay et al. (2014). The colour of anthocyanins is depending on the $\mathrm{pH}$ of the solution. The red colored pigments of anthocyanins are more stable at a lower pH (Coutinho et al., 2015). Most of the anthocyanin pigments have a high stability in acidic conditions and degradation occurs at higher $\mathrm{pH}$ (Katsumoto et al., 2007).

The total anthocyanin content in pure juices and mixtures was significantly affected by storage duration. A decrease in anthocyanin concentrations was observed during the first 7 days of storage. An extended storage up to 14 days increased the anthocyanin contents for Gabsi juice and its mixtures. Kalt and McDonald (1996) also reported that anthocyanins in blueberry increased by $18 \%$ during 2 weeks of refrigerated storage. The accumulation of anthocyanins in red orange juice during cold storage could be related to the expression of their key biosynthetic enzymes PAL, UFGT, CHS and DFR. PAL was the most induced transcript (Lo Piero et al., 2005). However, the pure juice 'Tounsi' and juice blends containing sweet juice 'Tounsi' and sour juices at different percentages showed a significant decrease of total anthocyanin contents during 2 weeks of storage. These results are following those reported by Muzaffar et al. (2017). However, Galani et al. (2017) reported that refrigerated storage during 15 days did not significantly influence total anthocyanin content in pomegranate juice. The loss of anthocyanins could be due to their degradation caused by polyphenol oxidase (PPO) and peroxidase (POD) (Zhang et al., 2005).

\section{Microbiological assessment}

The microbiological load of pure juices and juice blends estimated through total bacterial count is depicted in Table 4. Microbial count values ranged from 2.62104 to 3.65104 $\mathrm{CFU} / \mathrm{mL}$ for sweet juices 'Gabsi' and 'Tounsi'. Higher values were recorded in sour pomegranate juices that varying between 5.5105 for Garoussi 2 (GR2) and 7.92105 for Mezzi1 (MZ1). These juices were proved rich in total soluble solids and had a lower $\mathrm{pH}(\leq 3.5)$ (Table 4$)$. Previous studies revealed that acidic conditions are a suitable medium for microorganisms growing especially yeasts (Tribst, 2009; Suárez-Jacobo et al., 2010). The blending of sour and sweet pomegranate juices did not have a significant effect on the total aerobic plate count as compared to those in sweet juices. However, the juice blends TN-MZ1 10\% and TN-MZ1 20\% showed a significant increase of microbial count values (1.63 105 and 4.99105 , respectively).

Aerobic bacteria count values obtained in this study were higher than those (5.2 103 to $4.7103 \mathrm{CFU} / \mathrm{mL}$ ) reported by Alighourchi et al. (2008) and Varela-Santos et al. (2012). Many factors such as harvesting, transportation, raw materials, temperature and storage duration, as well as equipment sanitation all affect the microbiological nature of the product. The storage has been shown to significantly affect the aerobic bacteria count in both pure juices and juice blends. An increase was observed for pure juices and juice mixtures during 7 days of storage. The sour juice 'Mezzi 1'had the highest total bacterial count (3.73 106 CFU/mL), while the juice blends GB-GR2 10\% and GB-GR2 20\% presented the lowest values (3.6 $104 \mathrm{CFU} / \mathrm{mL}$ and $5104 \mathrm{CFU} / \mathrm{mL}$, respectively). A prolonged storage period up to 14 days resulted in a huge increase of total aerobic bacterial counts. The highest values (5.4 $106 \mathrm{CFU} / \mathrm{mL})$ were observed in the sour juice 'Mezzi 1', juice blends TN-MZ1 20\% and TN-MZ2 $20 \%$. Varela-Santos et al. (2012) also observed a high microbial load of total aerobic bacteria, reaching counts higher than $106 \mathrm{CFU} / \mathrm{mL}$ on the 13th day of refrigerated storage for pomegranate juice. The specifications for fruit juices served in the Gulf region recommend that the maximum permitted for total aerobic bacterial count should be 5104 (Gulf Standards, 2000; Geta et al., 2018). So, according to the Gulf standards, the microbiological quality of fresh sweet juices and juice blends, except Garoussi2 (GR2), Mezzi1 (MZ1), Mezzi2 (MZ2), GB-MZ1 20\%, GB-MZ2 20\%, TNMZ1 10\% and TN-MZ1 20\%, was found to be satisfactory for consumption.

Refrigerated storage for 7 days revealed a significant increase of total bacterial counts, which those of juice blends GB-GR2 $10 \%$ and GB-GR2 $20 \%$ only were within the limits of the Gulf standards. However, the microbial counts of juice beverages stored during 14 days exceeded the standard by a considerable margin. Fermentation, gas production, unpleasant odors, and increased turbidity of juices and swellings of the containers were principal characteristics of stored juice samples, particularly juice blends TN-MZ1 $10 \%$ and TN-MZ1 20\%. Fruit juices are suitable environment for specialized deteriogenic microorganisms, particularly bacteria and yeast. These microorganisms may cause the deterioration of juices by degrading some of their compounds (such as carbohydrates, protein and vitamins), producing undesirable odour and off-flavour, coloration, $\mathrm{pH}$ and texture changes (Batra et al., 2018). The current study revealed that the sour pomegranate variety Mezzi 1 (MZ1) wasn't suitable for juice blending, because of the too high microbial load. However, the mixtures made by sour juice Garoussi 2 (GR2) showed an acceptable microbiological quality even after 7 days of storage.

\section{Sensory Evaluation}

Sensory evaluation is an important quality criterion in foods. The panelists were asked to assess the colour, aroma, sourness, sweetness and overall acceptance of different juice samples (Figure 1). Pomegranate sour juices mainly 'Mezzi 1' and 'Mezzi 2' had not rated moderate to satisfactory scores. Their lower acceptance was due to the sensing of a high acid taste. As Tunisian panelists, Spanish and American ones did not prefer to consume pomegranate juice from the sour varieties (Vazquez-Araujo et al., 2010; Carbonell-Barrachina et al., 2012). It was observed that the highest sensory scores were obtained with the incorporation of $10 \%$ of pomegranate sour juices in the juice blends. Significant differences were found between beverages for colour acceptance. Colour sensory scores ranged from 5.1 for sour juice 'Mezzi 2' to 7.3 for GBMZ2 20\% mixture. It increased in juice blends proportionally to the percentage of sour juice added. Fresh juice blends made from the two sweet varieties 'Gabsi' and 'Tounsi' as well as sour juices were well appreciated by the panelists. However, juice mixtures made adding $20 \%$ of sour juice 'Mezzi 1' (GBMZ1 20\% and TN-MZ1 20\%) showed moderate acceptance scores. Panelists clearly identified the changes in sensory attributes during storage. 
Table 4. Changes in total aerobic bacterial counts $(\mathrm{CFU} / \mathrm{mL})$ of pure juices and juice blends during refrigerated storage

\begin{tabular}{|c|c|c|c|}
\hline Juice type & Fresh juice & 7 days of storage & 14 days of storage \\
\hline Gabsi & $2.6210^{4 d B}$ & $2.910^{5 \text { ghtA }}$ & $3.0410^{5^{\mathrm{eA}}}$ \\
\hline Tounsi & $3.6510^{4 d C}$ & $3.310^{5 f g h A B}$ & $6.4510^{5 \mathrm{deA}}$ \\
\hline GR2 & $5.510^{5 b c B}$ & $8.6410^{5 b c d A B}$ & $1.3110^{6 \mathrm{deA}}$ \\
\hline MZ1 & $7.9210^{5 a B}$ & $3.7310^{6 a A B}$ & $5.510^{6 a A}$ \\
\hline MZ2 & $6.8610^{5 a b B}$ & $9.310^{5 b c B}$ & $3.7610^{6 b A}$ \\
\hline GB-GR2 10\% & $1.2910^{4 d B}$ & $3.610^{4^{i B}}$ & $7.7510^{5 \text { deA }}$ \\
\hline GB-GR2 20\% & $1.44510^{4} d B$ & $510^{4 i B}$ & $8.2810^{5 \mathrm{deA}}$ \\
\hline GB-MZ1 10\% & $4.410^{4} d C$ & $1.0510^{5 h i B}$ & $9.38 \quad 10^{5 \text { deA }}$ \\
\hline GB-MZ1 20\% & $6.3510^{4 d C}$ & $1.3710^{\text {shiB }}$ & $1.5410^{6 \mathrm{cdeA}}$ \\
\hline GB-MZ2 10\% & $4.4510^{4 d C}$ & $1.3610^{5 h i B}$ & $1.2510^{6 \mathrm{deA}}$ \\
\hline GB-MZ2 20\% & $7.7510^{4 d C}$ & $5.5810^{5 e B}$ & $2.7310^{6 b c A}$ \\
\hline TN-GR2 10\% & $4.2910^{4^{d C}}$ & $3.310^{5 f g h B}$ & $1.03510^{6 \mathrm{deA}}$ \\
\hline TN-GR2 20\% & $5.1510^{4 d C}$ & $4.2510^{5 e f g B}$ & $1.3010^{6 \mathrm{deA}}$ \\
\hline TN-MZ1 10\% & $1.6310^{5 c B}$ & $7.7510^{5} d A B$ & $1.910^{6 c d A}$ \\
\hline TN-MZ1 20\% & $4.9910^{5 c C}$ & $1.0910^{6 b A B}$ & $5.5010^{6 a A}$ \\
\hline TN-MZ2 10\% & $1.5910^{4^{d C}}$ & $5.4510^{5} e^{e f B}$ & $1.810^{6} \mathrm{cdA}$ \\
\hline TN-MZ2 20\% & $2.5610^{4 d C}$ & $8.6410^{5 b c d B}$ & $5.6310^{6 a A}$ \\
\hline
\end{tabular}

Different lowercase letters within a same column indicate significant differences among juice types for each storage duration at $\mathrm{P}<0.05$ level.

Different uppercase letters within a same row indicate significant differences among storage duration treatments for each juice type at $\mathrm{P}<0.05$ level.

GB: Gabsi, TN: Tounsi, GR2: Garoussi 2, MZ1: Mezzi 1, MZ2: Mezzi 2
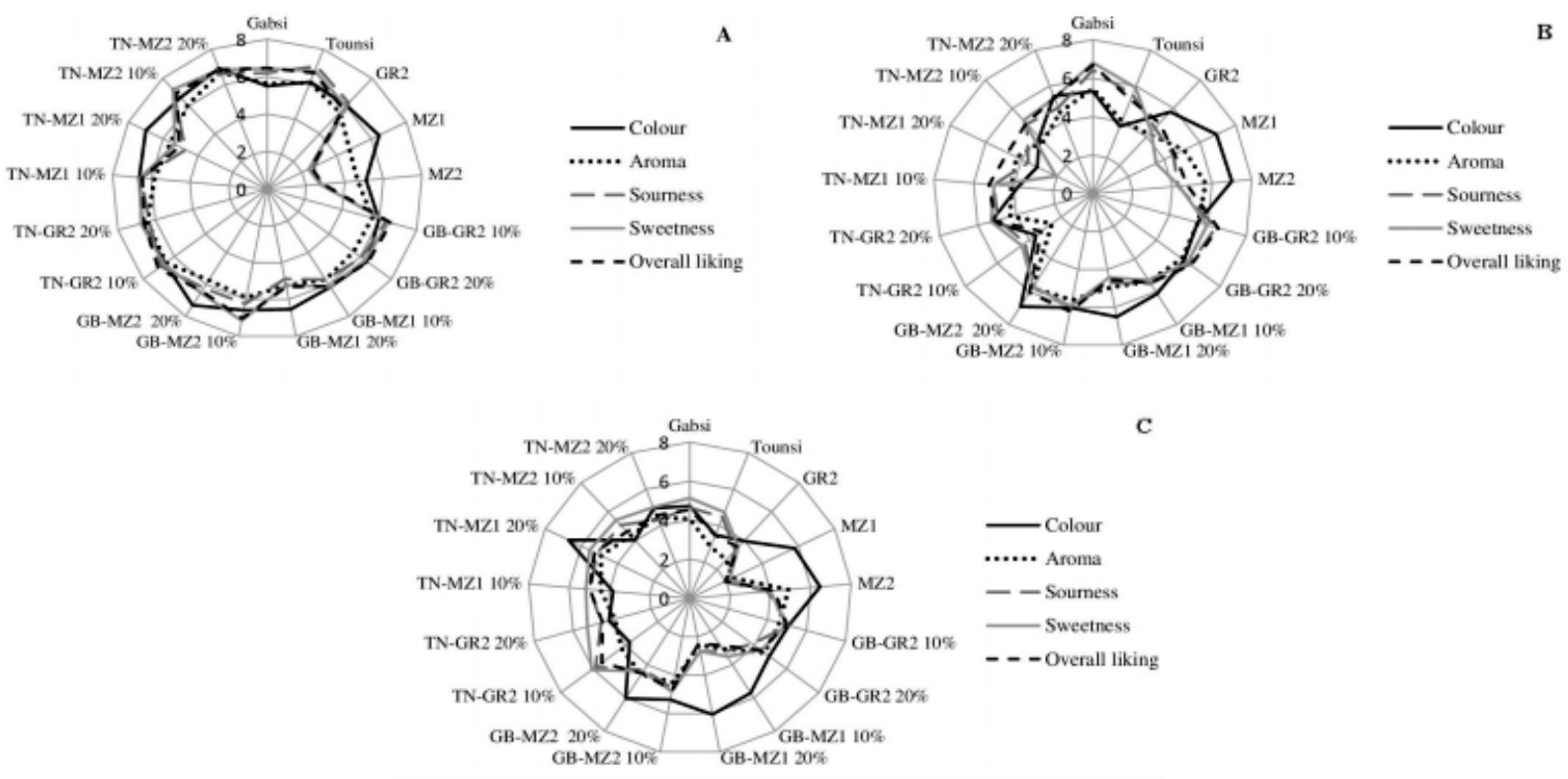

Figure 1. Changes in panelists' scores on their satisfaction degree for the sensory attributes and their overall liking of pure juices and juice blends during refrigerates storage (A) Fresh Juice; (B) 7 days storage; (C) 14 days of storage 
The mixtures containing 'Gabsi' sweet juice were more appreciated by panelists as compared to mixtures prepared from 'Tounsi' sweet juice after 7 days of storage. 'Gabsi' pure juice and GB-GR2 10\% mixture provided also good overall sensory quality during the first week of storage. Extending storage period till 14 days engendered a decrease in attribute scores. Changes in aroma, sourness and sweetness were considerably noticeable after an extended storage time. All beverages were moderately disliked by panelists excepting 'Mezzi 1' sour juice which was extremely disliked after two weeks of storage. Also, Gabsi - Mezzi 1 mixture was one of the least accepted beverages after 14 days of storage. It was considered turbid, fermented and described as having an unpleasant flavor, with less character of pomegranate.

\section{Correlation between physico-chemical and sensory parameters}

The correlation was conducted to determine the relationship between physico-chemical and sensory analyses (Table 5). The Pearson correlation coefficients estimated showed that the titratable acidity was negatively associated with sourness satisfaction degree, that influenced negatively overall liking.
Thus, acidity was shown as an important influential factor in consumer preference. Conversely, a significant positive correlation was found between total soluble solids content and overall liking. Total anthocyanin content was positively correlated with colour satisfaction degree, which it was positively associated with overall quality. Also, anthocyanins was found to have an impact on the flavour perception of beverages and thus consumers' preference.

Accordingly, the high anthocyanin content and resulting red colour, as well as balance between sweetness and acidity influenced significantly consumers' preference. However, it is interesting to notice that the panelists have evaluated the beverages based on sweet and acid taste intensities more than colour. The mixtures made by sweet juice Gabsi 'GB' and sour juices Garoussi 2 'GR2' and Mezzi 2 'MZ2' (10\% and $20 \%$ proportions) were the most appreciated by panelists. These beverages presented high total anthocyanin contents, red colour and taste well appreciated. However, only the beverages GB-GR2 10\% and GB-GR2 20\% showed acceptable microbial loads within permissible limits even after storage for one week.

Table 5. Pearson correlation coefficients between physico-chemical and sensory parameters TAC : total anthocyanin content ; TPC : total phenolic content ; SD : satisfaction degree ; OQ : overall quality

\begin{tabular}{|c|c|c|c|c|c|c|c|c|c|}
\hline TA & 1 & & & & & & & & \\
\hline $\mathrm{pH}$ &,$- 815^{* *}$ & 1 & & & & & & & \\
\hline TSS &, $323^{* *}$ & $-263^{* *}$ & 1 & & & & & & \\
\hline TAC &,$- 559^{* *}$ & , 305* &,$- 173^{\circ}$ & 1 & & & & & \\
\hline TPC &, $498^{* *}$ &,$- 460^{* *}$ &, $389^{* *}$ &,$- 364^{* *}$ & 1 & & & & \\
\hline Colour SD &, $216^{* *}$ &,$- 373^{* *}$ &,- 018 &, $326^{*}$ &,- 111 & 1 & & & \\
\hline Sourness SD &,$- 519^{* *}$ & $486^{*}$ & $191^{\circ}$ &, $541^{* *}$ &,$- 222 * *$ &, $281^{* *}$ & 1 & & \\
\hline Sweetness SD &,$- 570^{* *}$ & ,502* &, 140 &, $546^{*}$ &,$- 244^{* *}$ &, $262^{* *}$ &, $950^{* *}$ & 1 & \\
\hline \multirow[t]{2}{*}{ OQ } &,$- 462 * *$ & $370^{*}$ &, $232 * *$ &, $546^{* *}$ &,$- 169^{\circ}$ &, $346^{* *}$ & ,955"* &, $901 * *$ & 1 \\
\hline & TA & $\mathrm{pH}$ & TSS & TAC & TPC & $\begin{array}{l}\text { Colour } \\
\text { SD }\end{array}$ & $\begin{array}{c}\text { Sourness } \\
\text { SD }\end{array}$ & $\begin{array}{c}\text { Sweetness } \\
\text { SD }\end{array}$ & $\mathrm{OQ}$ \\
\hline
\end{tabular}

*Significance at $\mathrm{P}<0.05 * *$ Significance at $\mathrm{P}<0.01$.

\section{CONCLUSION}

Diverse pomegranate varieties, ranging from sweet to sour, may be used in the formulation of beverages with specific quality. The juice blends proved to be rich in total soluble solids, total anthocyanin and total phenolic contents. An attractive red colour of mixtures was observed proportionally to the percentage of sour juice added. After 7 days of storage, the juice blends retained their chemical properties providing a stable and attractive red colour, high total phenolic and total anthocyanins contents. However, only the beverages GBGR2 $10 \%$ and GB-GR2 20\% presented a microbial load counts within the acceptable limits. Thus, the storage period should not exceed 7 days because of poor organoleptic quality due to off-odors and high aerobic bacterial count. The sour pomegranate variety 'Mezzi 1 ' is proved to be not suitable for blending juices. Further research is warranted for establish new combinations containing pomegranate juice and other fruit juices and additives in order to develop other new value added beverages.

\section{ACIKNOWLEDGMENT}

We gratefully acknowledge Mr Sadok Kammoun for his help in conducting microbiological analyses.

\section{REFERENCES}

Addo, M.G., Akanwariwiak, W.G., Addo-Fordjour, P. and Obiri-Danso, K. 2008. Microbiological and Sensory Analysis of Imported Fruit Juices in Kumasi, Ghana. Research Journal of Microbiology. 3(8): 552-558. doi: 10.3923/jm.2008.552.558

Alighourchi, H and Barzegar, M. 2008. Anthocyanins characterization of 15 Iranian pomegranate (Punica granatum L.) varieties and their variation after cold storage and pasteurization. European Food Research and Technology. 227: 881-887. doi: 10.1007/s00217-007-0799-1.

Arnous, A., Makris, D.P. and Kefalas, P. 2001. Effect of principal polyphenolic components in relation to antioxidant characteristics of aged red wines. Journal of Agriculture of Food Chemistry. 49: 57365742. doi: org/10.1021/jf010827s.

Batra, N.G., Sharma, A. and Agarwal, N. 2018. Evaluation of microbiological criteria and quality of packed fruit juices. International Food Research Journal. 25(2): 458-461.

Bhardwaj, R.L and Mukherjee, S. 2011. Effects of fruit juice blending ratios on kinnow juice preservation at ambient storage condition. African Journal of Food Science. 5(5): 281 - 286.

Carbonell-Barrachina, A.A., Calin-Sanchez, A., Bagatar, B., Hernandez, F., Legua, P., Martınez-Font, R. and Melgarejo, P. 2012. Potential of Spanish sour-sweet pomegranates (cultivar $\mathrm{C} 25$ ) for the juice industry. Food Science and Technology International. 18(2): 129-138. doi.org/10.1177/1082013211414783.

Cheng, G.W and Breen, B.J. 1991. Activity of phenylalanyl ammonialyase (PAL) and concentrations of anthocyanins and phenolics in developping strawberry fruit. Journal of the American Society for Horticultural Science. 116: 865-868. doi.org/10.21273/JASHS.116.5.865. 
Coutinho, I.B., Freitas, A., Maçanita, A.L. and Lima, J.C. 2015. Effect of water content on the acid-base equilibrium of cyanidin-3-glucoside. FoodChemistry.172:476-480. doi.org/10.1016/j.foodchem.2014.09.060.

De Corrêa Souza, M., Cristina, M., Benassi, M. D. T. and De Almeida, R. F 2004. Stability of unpasteurized and refrigerated orange juice. Brazilian Archives of Biology and Technology. 47: 391-397. doi. 10.1590/S1516-89132004000300009.

Galani, J.HY., Patel, J.S., , Patel, N.J. and Talati, J.Y. 2017. Storage of Fruits and Vegetables in Refrigerator Increases their Phenolic Acids but Decreases the Total Phenolics, Anthocyanins and Vitamin $\mathrm{C}$ with Subsequent Loss of their Antioxidant Capacity. Antioxidants. 6: 59. doi. 10.3390/antiox6030059.

Geta, K., Kebede, A. and Chemedissa, M. 2018. Microbiological Safety of Fruit Juices Consumed in Cafes and Restaurants of Debre-Markos Town, North Western Ethiopia. Preprints, 2018060027. doi. 10.20944/preprints201806.0027.v1.

Gonzalez-Molina, E., Moreno, D.A. and Garcia-Viguera, C. 2009. A new drink rich in healthy bioactives combining lemon and pomegranate ju ices. Food Che mistry.115: $1364-1372$. doi.org/10.1016/j.foodchem.2009.01.056.

Gulf Standards. 2000. Microbiological criteria for food stuffs-part 1. GCC, Riyadh, Saudi Arabia, 7-20.

Hasnaoui, N., Mars, M., Ghaffari, S., Trifi, M., Melgarejo, P. and Hernandez, H. 2011. Seed and juice characterization of pomegranate fruits grown in Tunisia: Comparison between sour and sweet cultivars revealed interesting properties for prospective industrial applications. Industrial Crops and Products . 33: 374-381. doi.org/10.1016/j.indcrop.2010.11.006.

Hossain, M. Shishir, M., Saifullah, M.R.I., Sarker, M., Safeuzzaman, K.U. and Rahman, M. A. 2016. Production and Investigation of Biochemical and Organoleptic Changes of Mixed Fruit Juice during Storage Period. - Indian Journal of Nutrition Diet. 3(1): 119- 126.

Kalt, W and McDonald, J.E. 1996. Chemical Composition of Lowbush Blueberry Cultivars. Journal of the American Society for Horticultural Science. 121(1): 142-146. doi.org/10.21273/JASHS.121.1.142

Karpagavalli, B and Amutha, S. 2015. Influence of storage condition on the antioxidant activity of pomegranate squash. Plant Archives. 15(1): 405-410.

Katsumoto, Y., Fukuchi-Mizutani, M., Fukui, Y., Brugliera, F., Holton, T.A., Karan, M., Nakamura, N., Yonekura-Sakakibara, K., Togami, J., Pigeaire, A., Tao, G.Q., Nehra, N.S., Lu, C.Y., Dyson, B.K., Tsuda, S., Ashikari, T., Kusumi, T., Mason, J.G. and Tanaka, Y.2007. Engineering of the rose flavonoid biosynthetic pathway successfully generated blue-hued flowers accumulating delphinidin. Plant Cell Physiology. 48(11): 1589-1600. doi.org/10.1093/pcp/pcm 131.

Khoo H.E., Azlan, A., Tang, S.T. and Lim, S.M. 2017. Anthocyanidins and anthocyanins: colored pigments as food, pharmaceutical ingredients, and the potential health benefits. Food Nutrition and Research. 61(1): 1361779. 10.1080/16546628.2017.1361779.

Lo Piero, A. R., Puglisi, I., Rapisarda, P. and Petrone, G. 2005. Anthocyanins Accumulation and Related Gene Expression in Red Orange Fruit Induced by Low Temperature Storage. Journal of Agricultural and Food Chemistry. 53(23): 9083-9088. $10.1021 / \mathrm{jf051609 \textrm {s }}$

Mars, M. 2001. Genetic resources of pomegranate (Punica granatum L.) in Tunisia: Prospection, conservation and diversity analysis. Ph.D. Thesis in Natural Sciences. Tunis El Manar University, pp. 200.

Muzaffar, M., Nayik, G.A., Gull, A. and Kumar, P. 2017. Changes in quality characteristics of pomegranate juice concentrate during refrigerated storage. Journal of Postharvest and Technology. 5(3):16-21.

Nayik, G.H., Amin, T. and Bhat, S.V. 2014. Microbial analysis of some fruit juices available in the markets of Kashmir valley, India. Asian Journal of Microbioly Biotechnology and Environmental Science. 15(4): 733737.

Pontonio, E., Montemurro, M., Pinto, D., Marzani, B., Trani, A.,Ferrara, G.,Mazzeo, A.,Gobbetti, M. and Rizello, C.G. 2019. Lactic Acid Fermentation of Pomegranate Juice as a Tool to Improve Antioxidant Activity. Frontiers in Microbiology. 10: 1550. $10.3389 /$ fmicb. 2019.01550

Rommel, A., Heatherbell, D.A. and Wrolstad, R.E. 1990. Red Raspberry Juice and Wine: Effect of Processing and Storage on Anthocyanin Pigment Composition, Color and Appearance. Food Science. 55(4): 1011-1017. 10.1111/j.1365-2621.1990.tb01586.x.

Seeram, N.P., Aviram, M., Zhang, Y., Henning, S.M., Feng, L., Dreher, M. and Heber, D. 2008. Comparison of Antioxidant Potency of Commonly Consumed Polyphenol-Rich Beverages in the United States. Journal of Agriculture Food and Chemistry. 56: 1415-1422. 10.1021/jf073035s.

Suárez-Jacobo, Á., Gervilla, R., Guamis, B., Roig-Sagués, A.X. and Saldo, J. 2010. Effect of UHPH on indigenous microbiota of apple juice. A preliminary study of microbial shelf-life. International Journal of Food Microbiology. 136: 261-267. doi; 10.1016/j.ijfoodmicro.2009.11.011.
Tribst, A.A.L.,' SantAna, ADS. and de Massaguer, P.R. 2009. Review: Microbiological quality and safety of fruit juices - past, present and future perspectives. Critical Reviews in Microbiology. 35(4),: 310-339. doi. $10.3109 / 10408410903241428$.

Vardin, H. and Fenercioglu, H. 2003. Study on the development of pomegranate juice processing technology: clarification of pomegranate juice. Nahrung 42: 300-303. doi.org/10.1002/food.200390070.

Varela-Santos, E., Ochoa-Martinez, A., Tabilo-Munizaga, G., Reyes, J.E., Pérez-Won, M., Briones-Labarca, V. and Morales-Castro, J. 2012. Effect of high hydrostatic pressure (HHP) processing on physicochemical properties, bioactive compounds and shelf-life of pomegranate juice. Innovative Food Science and Emerging Technologies. 13: 13-22. doi.org/10.1016/j.ifset.2011.10.009.

V'azquez-Ara'ujo, L., Chambers, IV E., Adhikari, K. and CarbonellBarrachina, 'A.A. 2010. Sensory and Physicochemical Characterization of Juices Made with Pomegranate and Blueberries, Blackberries, or Raspberries. Journal of Food Science. 75 (7): 398-404. doi.org/10.1111/j.1750-3841.2010.01779.x.

Vitti, M.C.D., Sasaki, F.F., Miguel, P., Kluge, R.A. and Moretti, C.L. 2011. Activity of Enzymes Associated with the Enzymatic Browning of Minimally Processed Potatoes. Brazilian Archives of Biology and Technology. 54(5): 983-990. doi.org/10.1590/S151689132011000500016.

Walker, G.M. and Stewart, G. 2016. Saccharomyces cerevisiae in the Production of Fermented Beverages. Beverages. 2: 30. 10.3390/beverages 2040030 .

Wisal, S.,Ullah, J., Zeb A. and Khan, M.Z. 2013. Effect of Refrigeration Temperature, Sugar Concentrations and Different Chemicals Preservatives on the Storage Stability of Strawberry Juice. International Journal of Engineering and Technology. 13(2): 160-168.

Zaouay, F., Hadj Salem, H., Labidi, R. And Mars, M. 2014. Development and quality assessment of new drinks combining sweet and sour pomegranate juices. Emirates Journal of Food and Agriculture. 26 (1): 01-08. doi.org/10.9755/ejfa.v26i1.14838.

Zarfeshany, A., Asgary, S. and Javanmard, S.H. 2014. Potent health effects of pomegranate. Advanced Biomed Research. 3: 100. doi.10.4103/22779175.129371.

Zhang, Z., Pang, X., Xuewu, D., Jia, Z. and Jiang, Y. 2005. Role of peroxidase in anthocyanin degradation in litchi fruit pericarp. Food Chemistry. 90(1-2): 47-52. doi.org/10.1016/j.foodchem.2004.03.023. 